Session 3461

\title{
Meeting ABET Criterion 4 - From Specific Examples to General Guidelines
}

\author{
Jerry W. Gravander, Kathryn A. Neeley, Heinz C. Luegenbiehl \\ Clarkson University/University of Virginia/Rose-Hulman Institute of Technology
}

\begin{abstract}
"My students often asked me what the difference is between engineering and science. .. .I always told them that engineering is the stuff that works out in practice." Carver A. Mead, Professor Emeritus, California Institute of Technology, 2003 National Academy of Engineering Founders Award Recipient ${ }^{4}$

"The real world is messy and far more complicated than the neat, reductionist realm of scientists and engineers. ... In the real world, disparate components interact in complex systems." Erika Jonietz ${ }^{3}$
\end{abstract}

\begin{abstract}
Criterion 4 of the Accreditation Board for Engineering and Technology (ABET) Engineering Criteria 2000 requires that engineering curricula culminate in a major design experience that incorporates "engineering standards and constraints that include most of the following considerations: economic; environmental; sustainability; manufacturability; ethical; health and safety; social; and political." That is, Criterion 4 calls for an educational experience that integrates virtually everything students have learned, ranging from their technical engineering knowledge to their understanding of social and political issues. The other presentations in this session describe specific examples of how Criterion 4 is being met using a variety of multidisciplinary approaches. This paper reflects on these examples and formulates general guidelines based on them.
\end{abstract}

\section{Introduction}

A great deal of the discussion of ABET's Engineering Criteria 2000, including our own work, ${ }^{5,6}$ has focused on outcomes a-k of Criterion 3 . If, however, we consider the overall objective of preparing engineers for practice and the importance of integration within the engineering curriculum, it becomes apparent that Criterion 4 (reproduced below) merits at least as much attention. Criterion 4 emphasizes the role of constraints in engineering practice and overtly highlights the way that the entire curriculum should function as a system. Within that system, the major design component of the curriculum (highlighted in bold type in the table below) functions as a culminating experience and, ideally, gives students an understanding of 
how the knowledge and skills developed throughout the other parts of the curriculum come together in practice.

This paper is part of a session on the implementation of ABET Criterion 4. The other papers in the session consider specific examples being used to meet Criterion 4 through broadly multidisciplinary approaches. In the following we reflect on these examples and others and use them to develop a number of general guidelines for implementation of the design experience.

\section{Criterion 4. Professional Component}

The professional component requirements specify subject areas appropriate to engineering but do not prescribe specific courses. The engineering faculty must assure that the program curriculum devotes adequate attention and time to each component, consistent with the objectives of the program and institution. Students must be prepared for engineering practice through the curriculum culminating in a major design experience based on the knowledge and skills acquired in earlier course work and incorporating engineering standards and realistic constraints that include most of the following considerations: economic; environmental; sustainability; manufacturability; ethical; health and safety; social; and political. The professional component must include:

a.) one year of a combination of college level mathematics and basic sciences (some with experimental experience) appropriate to the discipline.

b.) one and one-half years of engineering topics, consisting of engineering sciences and engineering design appropriate to the student's field of study. The engineering sciences have their roots in mathematics and basic sciences but carry knowledge further toward creative application. These studies provide a bridge between mathematics and basic sciences on the one hand and engineering practice on the other. Engineering design is the process of devising a system, component, or process to meet desired needs. It is a decision making process (often iterative), in which the basic sciences, mathematics, and the engineering sciences are applied to convert resources optimally to meet these stated needs.

c.) a general education component that complements the technical content of the curriculum and is consistent with the program and institution objectives. ${ }^{1}$

Guidance with respect to the content of the "general education component" mentioned in Criterion 4 can be found in Criterion 3, Program Outcomes and Assessment. Many of the sub-criteria in this section encompass knowledge and abilities in mathematics, basic science, and engineering science and design, which relate to components (a) and (b) of Criterion 4. However, four of the components of Criterion 3 clearly relate to the "general education that complements the technical content" of engineering curricula: ${ }^{1}$

3f.) an understanding of professional and ethical responsibility.

3g.) an ability to communicate effectively. 
3h.) the broad education necessary to understand the impact of engineering solutions in a global and societal context.

3j.) a knowledge of contemporary issues.

In sum, the accreditation criteria for engineering call for an educational experience that lays a foundation of knowledge and ability across a broad range of disciplinary areas from engineering, mathematics, and science, to the humanities and social sciences, and that draws together virtually everything students have learned, ranging from their technical engineering knowledge to their understanding of social and political issues, in a culminating practicum that models actual engineering practice.

In many ways, the Criterion 4 requirement for a major design experience can be understood as a bridge between the student's academic experience and what is typically termed "the real world." And while the Criterion 4 requirement asserts that the engineering sciences "provide a bridge between mathematics and basic sciences on the one hand and engineering practice on the other," decades of experience suggest, as Carver Mead's quote asserts, that there is a significant difference between science (or the sciences) and practice. As Mead expressed it, "We were out in the research laboratory trying to figure out what was true. . . Of course, things that don't work in the lab don't work in the real world, but things that do work in the lab often take a long time to work out in the real world." Mead might also have added that things that work in the lab sometimes do not work at all in practice. The "bridge" between the engineering curriculum and engineering practice matters, then, because it educates students about the realities of the disjunction between the laboratory and practical application. Ideally, educational experiences that fulfill the Criterion 4 requirement give the students an understanding of the integrative nature of successful engineering designs.

\section{So Close But So Far Away? The Difficulties of Connecting with the Real World}

One of the most striking characteristics of discussions of "the real world" versus the world of engineering education is that the real world-despite its obvious presence as the context for both education and practice-seems elusive. To formulate and implement major design experiences in response to ABET 2000, we need to be specific about exactly what separates or distinguishes the real world from the academic world.

At one level, the opposite of "the real world" seems to be the laboratory or "the ivory tower." At another level, and as stated explicitly in the second quote that begins this paper, "the real world" is being opposed to the tidy, reductionist realm that is modeled in engineering textbooks, laboratories, and problem sets. The real world is, interestingly, both more and less constrained than the tidy, reductionist realm. It is more constrained in the sense that economics, concerns about environmental damage or manufacturability, or issues of ethics, unions, and user acceptability make themselves felt as powerful influences on the design and implementation process. In other words, they are palpable concerns that are directly experienced and need not be imagined. On the other hand, the real world is less constrained in the sense that the problem or opportunity being addressed through engineering analysis and design does not present itself as

Proceedings of the 2004 American Society for Engineering Education Annual Conference \& Exposition Copyright $\odot$ 2004, American Society for Engineering Education 
neatly bounded or clearly defined. This lack of constraints can be very disconcerting for students accustomed to well defined and clearly bounded problems.

The distinctions between the two realms are many, but among the most important are that the tidy realm:

1.) supposes that there is one right answer a given question.

2.) involves only one disciplinary perspective or discrete body of knowledge.

3.) is bounded more than it is constrained, largely because it is abstracted from context.

4.) deals with components rather than with systems.

5.) typically requires great powers of imagination to develop an understanding of the social and ethical context of the work in question.

The messy realm, on the other hand:

1.) supposes that there are many workable solutions but that, among workable solutions, some are much better than others.

2.) is broadly multidisciplinary.

3.) is unbounded and fully embedded in context.

4.) deals with systems rather than components.

5.) provides direct experience of the social and ethical impacts of technology and of the human and organizational dynamics that characterize the context of engineering practice.

Thus, the major design experience needs to introduce students to the messiness of "the real world," a sense of ambiguity and uncertainty that is an essential component of humanities, social science, and manage ment course content.

The need to acquaint engineering students with the messiness and constraints of engineering practice has long been recognized, and many approaches to closing the gap between education and practice have been identified. As early as 1919, the Mann Report, A Study of Engineering Education, urged the inclusion of what it termed "real work" constraints, such as "values and costs," and the establishment of closer linkages to industry and to the "human and social setting" of technology. ${ }^{2}$ Similar recommendations have appeared in subsequent reports since that time, which suggests two interesting conclusions: (1) that the gap the major design experience is designed to fill has been recognized for a long time and (2) that significant obstacles to closing the gap exist. Required for overcoming the gap are an in-depth understanding both of what makes it difficult to close and a specification of which aspects of the gap are most important to close.

Many approaches have been tried. One is to simulate the "real world" environment by bringing it to students in the form of problems drawn from the context of academia or research labs. Another approach has been to take the student out into the "real world" through internships, service-based learning, and similar activities. Yet another approach has been to connect students with "real world" clients who will make use of their results. This last approach can present particular difficulties because there is seldom a good fit between academic years and schedules

Proceedings of the 2004 American Society for Engineering Education Annual Conference \& Exposition Copyright $\odot$ 2004, American Society for Engineering Education 
and the needs of industry. The results orientation of external clients is both an asset and a problem — an asset because it replicates an important feature of the world of practice, a problem because failure is often not an option from the client's point of view, while we must always view it as a possibility in an academic setting. Another problem has been that the departmental structures that characterize university settings are not at all suited to the organization of multidisciplinary activities. Thus, even when integrated curricula that incorporated multidisciplinary design experiences are developed, their scope is often limited to a particular degree program.

\section{Understanding the Role of Integration in the Major Design Experience and Criterion 4}

There is a clear assumption in Criterion 4 that students' culminating engineering design project should demonstrate a wholeness or integration of parts, rather than being a collection of disparate elements that are cobbled together. Both Criterion 3 and Criterion 4 make it clear that these integrated parts include knowledge and abilities from the humanities and social sciences as well as from the technical areas of the curriculum. Since students cannot integrate knowledge and abilities they do not have, these criteria are calling for course work and educational experiences throughout the four years that ground students in the concepts and methods of the humanities and social sciences. Moreover, since students cannot integrate liberal knowledge and abilities successfully without practice, these criteria also are calling for engineering curricula to give them this practice and thereby develop students' ability to produce an integrated multidisciplinary design. There exists a long history of approaches to integrating humanities and social science content to make capstone engineering design courses more "real world" and less abstracted from the context of engineering practice, a history replete with many failures and a few long-term successes. A constant throughout, however, is the recognition that the humanities and social sciences are essential for helping students understand not only the messiness of the "real world" but also the ways that components of very different types interact in complex systems.

A full understanding of the integration of humanities and social sciences content in capstone design courses requires a systematic approach, beginning with the identification of particular instances of successful integration, and then generalizing to methods and concepts that can be adapted globally in all engineering curricula. Presently there is no consensus about such global approaches, and the work of identifying examples and deriving general principles from them remains to be done. This paper makes an initial contribution toward this work.

Instances of successful integration can be analyzed only after they have been identified, and this requires some basis for making the identification. One approach to clarifying a concept is to develop a definition. The following one captures the core meaning of "integration" as used in this paper to analyze the examples of multidisciplinary capstone design experience that are presented in the other papers of this session. "Liberal (i.e., the humanities and social sciences) and technical education are integrated within the engineering enterprise if and only if both the liberal and technical faculty engaged in this enterprise (1) recognize the fundamental importance and value of liberal learning not only in the education of engineers but in engineering design and practice and, moreover, (2) develop and implement the engineering educational experience so

Proceedings of the 2004 American Society for Engineering Education Annual Conference \& Exposition Copyright $(0)$ 2004, American Society for Engineering Education 
that students understand the integral contribution that liberal learning has made to their education and will make to their professional practice." Note that while this definition neither specifies nor rules out particular types of courses or curricular experiences, it does rule out a common approach to liberal learning for engineering students, namely, sending them off without guidance to other areas of the university to take whatever humanities and social science courses fit their schedules and then never incorporate what students learn in their subsequent engineering courses.

Another approach is to develop a set of criteria for distinguishing between an integrated humanities and social sciences (HSS)-engineering educational experience and one that is not. The following criteria capture the essence of an educational experience that we consider to be integrated. In large part these criteria will be relevant regardless of the size or structure of the integrative project.

1.) Integrated curriculum planning is supported on an ongoing basis by the institution:

- both HSS and engineering faculty are involved and carry equal weight in discussions and decisions.

- the HSS faculty include people who have knowledge of engineering practice and the contexts in which engineers typically function.

- the planning group has institutional support that allows continuity over time and adequate resources in the present.

- the institution has a comprehensive plan for liberal education that provides a coherent, integrated HSS-engineering experience for all engineering students.

2.) Identifiable points in the curriculum where an explicit connection is made between the HSS and engineering:

- a single course would not be adequate, but the entire curriculum need not be integrated for the program to be characterized as integrated.

- the connections are made in different types of courses, i.e., predominantly engineering, predominantly HSS, explicitly interdisciplinary, capstone design courses, etc.

- the connections are made at different stages in the students' education.

3.) Distribution of the teaching burden for the integrative elements of the curriculum:

- both technical and HSS faculty contribute to instruction, that is, teach courses in which the connections are made.

4.) Student and faculty awareness of the integrated character of the curriculum:

- the faculty and students involved understand and can articulate (in circumstances such as interviews) the rationale for taking an integrated approach to engineering education; the specific ways in which the curriculum makes connections; and the 
extracurricular mechanisms through which students can make connections of their own.

5.) In cases where the HSS courses taken by engineering students must also meet the institution's general education requirements:

- general education requirements are compatible with integration of the HSS courses into the engineering educational experience.

6.) The engineering curriculum provides students with project or problem-based learning experiences in which they must draw on their liberal learning to achieve a successful result, and students consistently are able to do so. ( $C f$., ABET EC 2000, Criterion 4. ${ }^{1}$ )

These criteria are meant to be indicators that particular courses, programs, educational experiences, or curricula do indeed integrate the HSS and engineering education in the sense used in this paper. An instance that meets the definition of integration given above undoubtedly also will meet some combination of these indicators, whereas an instance that fails to meet any of them undoubtedly also could not satisfy the definition. As such, the indicators not only help identify instances of successful integration, they also provide dimensions along which an institution could move in order to achieve integration.

\section{Implementation Recommendations: the Meaning and Practice of Integration within the Engineering Curriculum and the Major Design Experience}

The papers in this session have presented several approaches to and instances of multidisciplinary design, both capstone courses and sequences of preparatory experiences culminating in such courses. These succeed in integrating the liberal with the technical because they exhibit the following characteristics.

\section{1.) Understanding Integration as Central to the Major Design Experience and}

Engineering Practice. If students are to get maximum advantage of their major design experience, it is crucial for them to understand that

- Integration of different forms of knowledge and the various constraints is an essential feature of the major design experience.

- Understanding the interconnectedness of different elements and different forms of knowledge is essential for the effective use and implementation of engineered products and solutions in the world.

- Integration involves synergistic combination of knowledge, a creative process in which the whole solution that emerges is more than the sum of the parts.

- Integration means recognizing all elements as indispensable (rather than establishing a hierarchy in which some are central and others peripheral) and doing with away concepts such as "internalities" and "externalities."

- An integrated approach is more "realistic," i.e., more attuned to the realities of engineering practice, than are the compartmentalized, disciplinary, or otherwise 
limited approaches that they have been exposed to throughout most of their education.

2.) Support Students by Teaching Them to Integrate. Because the breadth of perspective and habits of mind required for integration place significant demands on students, they will require support and instruction in developing a broad and integrated understanding of both design problems and design solutions. Thus, students need

- Integrative frameworks that help them understand the reasons why engineering organizations and enterprises now tend to focus on the design of entire systems rather than the production of discrete components, i.e., a rich understanding of the context of engineering practice and design.

- Faculty who understand the value of an integrated approach, including the insights provided by the humanities and social sciences (HSS).

- An understanding that human, environmental, and other ethical considerations are essential in the development and implementation of new technology.

- The broad educational background and research skills necessary for discovering and exploring the less obvious constraints and dimensions of the problem.

- Guidance in developing the ability to engage in the interdisciplinary dialogue that is essential for developing an integrated understanding of any engineering problem or the implementation of any engineering design.

3.) Unders tand the Crucial Role of the HSS. The HSS are essential to developing contextual skills, but the HSS can only contribute if students see the connections between insights from the HSS and the practice of engineering.

- These connections should be developed at the outset and reiterated throughout the curriculum that precedes the major design experience.

- Encourage feedback from the world outside academia affirming the value of integrative educational experiences.

4.) View the Criterion 4 Requirement and the Major Design Experience as Part of a Comprehensive, Integrated Curriculum.

- Recognize the broad foundations that are required.

- Choose design contexts and problems that will make constraints real.

A commitment to take educational advantage of the opportunities provided by the new ABET accreditation criteria brings with it the responsibility to foster the integrative abilities of engineering students. Rather than meeting the learning outcomes listed in the criteria by tacking on a variety of non-technical courses to a primarily technical educational experience, institutions can begin to develop curricula that provide a bridge between students' relatively discrete courses and the non-discrete world they will encounter in their post-graduate life. In this paper we have set out some basic presuppositions of taking the latter route. We recognize that following this path will require a great deal of institutional support, but we also believe, as the examples in this 
session demonstrate, that it has the potential to be an invaluable experience both for participating faculty and for student engineers embarking on their careers.

Bibliography

1. "Criteria for Accrediting Engineering Programs: Effective for Evaluations During the 2004-2005 Accreditation Cycle," Accre diting Board for Engineering and Technology, http://www.abet.org (accessed January 8, 2004).

2. Steven L. Goldman, "The History of Engineering Education : Perennial Issues in the Supply and Training of Talent." Contractor Report published as part of Higher Education for Science and Engineering - A Background Paper.” OTA-BP-SET-52. U.S. Congress, Office of Technology Assessment. (Washington, D.C.: U.S. Government Printing Office, March 1989). The citation here is from Appendix D "A Chronology of Reports on Engineering Education," which is available at <http: www.wws.princeton.edu/cgibin/byteserve.prl/ ota/disk1/1989/8919/891910.pdf>. Accessed January 12, 2004.

3. Erika Jonietz. "A New System at MIT: Innovative Programs Address Engineering Technology and Biology as Systems.” Technological Review, December 2002/January 2003. Online edition. Available:

$<$ http://www.techreview.com/articles/print_version/jonietz1202.asp> Accessed January 12, 2004.

4. National Academy of Engineering. "2003 Founders Award Recipient Remarks." October 12, 2003. Available: <http: www.nae.edu/NAE/awardscom.nsf/weblinks/LRAO-5TCRZP?Open Document> Accessed January 12, 2004.

5. Liberal Studies and the Integrated Engineering Education of ABET 2000: Reports from a Planning Conference at the University of Virginia, April 4-6, 2002, available at http://www.tcc.virginia.edu/ec2000.

6. David F. Ollis, Kathryn A. Neeley, Heinz C. Luegenbiehl, eds., Liberal Education for $21^{\text {st }}$ Century Engineering: Responses to ABET/EC 2000 Criteria, New York: Peter Lang, 2004.

JERRY W. GRAVANDER is Head of the Division of Liberal Arts at Clarkson University. He has written and presented widely on liberal education for engineering students, as well as engineering ethics and the impacts of science and technology on society. He was the 1996 recipient of the Sterling Olmsted Award of ASEE's Liberal Education Division.

KATHRYN A. NEELEY is in the Division of Technology, Culture, and Communication of the School of Engineering and Applied Science of the University of Virginia. She has been a leader in the liberal education community's response to ABET Criteria 2000, and she has written and presented widely on this issue. She received the 2003 Sterling Olmsted Award of ASEE's Liberal Education Division, and she is a past chair of the Division.

HEINZ C. LUEGENBIEHL is Professor of Philosophy and Technology Studies and Chair of the Humanities and Social Sciences Department at Rose-Hulman Institute of Technology. He has published and spoken extensively on liberal education for engineers, engineering ethics, and the social impact of technology. He received the 1998 Sterling Olmsted Award of ASEE's Liberal Education Division, and he is a past chair of the Division.

Proceedings of the 2004 American Society for Engineering Education Annual Conference \& Exposition Copyright $\odot$ 2004, American Society for Engineering Education 